\title{
KEBUTUHAN LAYANAN TRANSPORTASI UMUM BAGI PENGGUNA KURSI RODA DI JABODETABEK
}

\author{
Raymond Teng $^{1}$ dan Leksmono Suryo Putranto ${ }^{2}$ \\ ${ }^{1}$ Program Studi Sarjana Teknik Sipil, Universitas Tarumanagara, Jl. Letjen S. Parman No.1 Jakarta \\ raymond.325160058@stu.untar.ac.id \\ ${ }^{2}$ Program Studi Sarjana Teknik Sipil, Universitas Tarumanagara, Jl. Letjen S. Parman No.1 Jakarta \\ leksmonop@ft.untar.ac.id
}

\begin{abstract}
Public transportation is a service for transporting large quantities of passengers, managed with a specific schedule, having a fixed route, and charged a certain amount of cost on each trip. The most commonly used public transportation in Jabodetabek is KRL, MRT, and Transjakarta. Passengers using public transportation consist of disabled and non-handicapped. Wheelchair users use public transportation to support their daily activities. If there is a wheelchair users, public transportation company demanded to provide priority service. However, after a wheelchair-prioritized service is provided, a complaint from a wheelchair users appears. This article aims to anylize existing condition of public transportation service needs for wheelchair users with one sample T-Test method. The results defined the priority area and the presence of officers are less satisfy for wheelchair users. The Infrastructure such as lift, toilet, counter, corridor, access doos/exit, ramp, also gap for wheelchair users according to both respondents of wheelchair users are not satisfactory enough. Non-disability users are also not much provide assistance for wheelchair users.
\end{abstract}

Keywords: priority; wheelchair users; public transport

\begin{abstract}
ABSTRAK
Transportasi umum adalah layanan untuk mengangkut penumpang dalam jumlah banyak, dikelola dengan jadwal tertentu, memiliki rute yang tetap, dan dikenakan sejumlah biaya pada setiap perjalanan. Transportasi umum yang paling sering digunakan di Jabodetabek adalah KRL, MRT, dan Transjakarta. Penumpang yang menggunakan transportasi umum terdiri dari penyandang disabilitas dan non-disabilitas. Penyandang disabilitas pengguna kursi roda menggunakan transportasi umum untuk menunjang aktivitasnya sehari-hari. Terdapatnya pengguna kursi roda, membuat perusahaan transportasi umum dituntut untuk memiliki layanan priortias transportasi umum. Namun setelah diberikan layanan prioritas pengguna kursi roda, muncul keluhan dari pengguna kursi roda. Tulisan ini bertujuan untuk menganalisis kondisi eksisting kebutuhan layanan transportasi umum bagi pengguna kursi roda dengan metode One Sample T-Test. Hasil yang didapat menyatakan area prioritas dan keberadaan petugas kurang memuaskan bagi pengguna kursi roda. Infrastruktur seperti lift, toilet, loket, koridor, pintu akses masuk/keluar, ramp, juga celah untuk pengguna kursi roda menurut kedua responden pengguna kursi roda tidak cukup memuaskan. Pengguna non-disabilitas juga belum banyak yang memberikan bantuan untuk pengguna kursi roda.
\end{abstract}

Kata kunci: prioritas; pengguna kursi Roda; transportasi umum

\section{PENDAHULUAN}

Manusia merupakan makhluk yang diciptakan oleh Tuhan Yang Maha Esa dengan berbagai kelebihan dan kekurangan di dunia ini. Beberapa manusia mengalami halangan berupa cacat fisik yang mengakibatkan manusia harus menggunakan kursi roda. Hilangnya kemampuan fisik mengakibatkan penyandang harus menggunakan kursi roda. Hal ini dapat menghambat pergerakan penyandang cacat fisik di lingkungan sekitar, terutama pada transportasi umum. Maka dari itu, kebutuhan layanan transportasi umum bagi penyandang disabilitas harus ditingkatkan.

Dalam Undang-undang nomor 25 tahun 2009 tentang Pelayanan Publik definisi layanan publik adalah kegiatan atau rangkaian kegiatan dalam rangka pemenuhan kebutuhan pelayanan sesuai dengan peraturan perundang-undangan bagi setiap warga negara dan penduduk atas barang, jasa, dan/atau pelayanan administratif yang disediakan oleh penyelenggara layanan publik. 
Manusia dengan penyandang cacat fisik akan merasa kesulitan saat melakukan kegiatan sehari-hari, terutama pada saat ingin menggunakan layanan transportasi umum. Maka dari itu, mereka akan sangat membutuhkan fasilitas yang memadai agar mereka bisa mandiri.

Pembangunan fasilitas layanan transportasi umum di Jakarta, Bogor, Depok, Tangerang dan Bekasi (Jabodetabek) sebagian besar masih belum memenuhi standar minimum suatu konsep aksesibilitas. Hal tersebut dikarenakan penyedia layanan transportasi umum jarang memikirkan aksesibilitas yang baik untuk penyandang cacat fisik.

Rumusan masalah pada penelitian ini adalah apakah fasilitias layanan transportasi MRT, KRL, dan Transjakarta sudah cukup memadai bagi pengguna kursi roda. Karena dengan adanya fasilitas layanan transportasi yang memadai, mobilitas pengguna kursi roda dapat terpenuhi untuk menunjang kegiatan sehari-hari.

Berdasarkan masalah yang dirumuskan pada rumusan masalah, maka tujuan dari penulisan topik ini adalah mengetahui layanan fasilitas transportasi MRT, KRL, dan Transjakarta yang sudah atau belum memadai bagi pengguna kursi roda agar layanan yang belum memadai dapat ditingkatkan oleh perusahaan transportasi umum.

\section{Penyandang disabilitas secara umum}

World Health Organization (WHO) atau Badan Kesehatan Dunia mendefinisikan disabilitas sebagai " $A$ restriction or inability to perform an activity in the manner or within the range considered normal for a human being, mostly resulting from impairment". Definisi tersebut menyatakan dengan jelas bahwa disabilitas merupakan ketidakmampuan untuk melakukan suatu kegiatan dengan cara yang atau dalam rentang dianggap normal bagi manusia, sebagian besar akibat penurunan kemampuan. WHO mengutarakan bahwa kekurangan manusia dibagi menjadi 3 bagian, yaitu pelemahan (impairment), ketidakmampuan (disability), keterhambatan (handicap).

1. Pelemahan (Impairment) pada bidang kesehatan diartikan sebagai segala pelemahan atau keadaan tidak normal secara psikologis, fisiologis, struktur anatomi, atau fungsi. Impairment mempunyai karakteristik yang ditandai dengan kelainan yang bersifat sementara maupun permanen.

2. Ketidakmampuan (Disabilty) pada bidang kesehatan diartikan sebagai segala keterbatasan atau kekurangan (hasil dari impairment) untuk melakukan aktifitas yang dianggap normal.

3. Keterhambatan (Handicap) pada bidang kesehatan diartikan sebagai kerugian yang dihasilkan oleh impairment dan disability yang membatasi seseorang melakukan aktifitas yang normal untuk individu tersebut.

\section{Penyandang disabilitas pengguna kursi roda}

Penyebab manusia mengalami cacat fisik disebabkan oleh 2 faktor, yaitu cacat didapat dan cacat bawaan/lahir. Spinal Cord Injury atau cedera tulang belakang menjadi salah satu penyebab utama kecacatan dan pasien SCI dapat membutuhkan strategi rehabilitas yang ketat dan beberapa modifikasi perangkat bantu yang berbeda untuk mencapai kualitas hidup yang lebih baik (Munce, et al., 2013).

Penderita paraplegia (kehilangan kekuatan atau pergerakan akibat cedera) akibat spinal cord injury dapat berjalan lagi menggunakan teknologi seperti Functional Neuromuscular Stimulation (Kobetic \& Marsolais, 1997), reciprocal gait orthoses (Douglas, Larson, D'Ambrosia, \& McCall, 1983), powered exoskeletons (Louie, Eng, \& Lam, 2015), dan, hybrid neuroprotheses (Kobetic, et al., 2009).

\section{Hambatan aksesibilitas penyandang disabilitas}

Tujuan dihilangkannya berbagai hambatan yang merintangi para penyandang disabilitas untuk berpartisipasi dalam kegiatan masyarakat di transportasi umum yang tersedia. Menurut Tarsidi (2011) ada 2 macam hambatan akses, yaitu hambatan arsitektural dan hambatan informasi dan komunikasi. Pengguna kursi roda sering kali menghadapi hambatan arsitektural, yang mencakup seperti:

1. Perubahan ketinggian yang siknifikan seperti pada parit atau tangga

2. Tidak ada ramp antara trotoar dan jalan

3. Tidak cukupnya ruang lutut di bawah meja atau wastafel

4. Tidak cukupnya ruang untuk berbelok

5. Permukaan jalan yang tidak rata

6. Pintu yang berat dan sulit dibuka

7. Tombol yang terlalu tinggi untuk dicapai 


\section{METODE PENELITIAN}

Metode penelitian yang digunakan dalam penelitian ini adalah pengambilan kuesioner. Kuesioner dibagikan kepada responden tertentu dengan harapan mendapat respon atas pertanyaan tersebut. Pertanyaan pada penelitian kondisi eksisting layanan transportasi umum bagi pengguna kursi roda yang terbagi menjadi beberapa variabel, yaitu area prioritas, keberadaan petugas, infrastruktur, pengaruh non-disabilitas terhadap pengguna kursi roda, fasilitas lift dan toilet pada stasiun MRT/KRL, dan Akses masuk/keluar pada halte Transjakarta. Bagian selanjutnya adalah pertanyaan tingkat kepentingan upaya untuk meningkatkan kebutuhan layanan transportasi umum bagi pengguna kursi roda dengan 5 pilihan untuk MRT/KRL, yaitu penambahan petugas, perluasan area prioritas, perluasan akses pintu masuk/keluar stasiun, perluasan akses pintu masuk/keluar kereta, dan perluasan area toilet prioritas. Juga 4 pilihan untuk Transjakarta, yaitu penambahan petugas, perluasan area prioritas, perluasan akses pintu masuk/keluar halte, dan perluasan akses pintu masuk/keluar bus.

Pada bagian kondisi eksisting layanan transportasi umum bagi pengguna kursi roda dijawab responden menggunakan skala likert. Nilai-nilai tersebut didefinisikan sebagai berikut angka 1 sangat tidak setuju, angka 2 tidak setuju, angka 3 setuju, dan angka 4 sangat setuju seperti yang terdapat pada tabel 1. Penelitian yang dilakukan akan diolah dengan metode One Sample T-Test. Penelitian ini mengambil nilai tes sebesar 2,5 (peralihan dari kondisi tidak setuju ke setuju) pada selisih rataan.

Tabel 1. Penilaian tingkat ketersediaan layanan transportasi umum bagi pengguna kursi roda

\begin{tabular}{cc}
\hline Nilai & Keterangan \\
\hline 1 & Sangat tidak Setuju \\
2 & Tidak Setuju \\
3 & Setuju \\
4 & Sangat Setuju \\
\hline
\end{tabular}

\section{HASIL DAN PEMBAHASAN}

Responden yang ikut serta dalam penelitian ini berjumlah 30, yang terdiri dari 18 responden non-disabilitas dan 12 responden pengguna kursi roda. Data-data umum yang diperoleh dalam penelitian ini meliputi jenis kelamin responden, usia responden, pekerjaan responden, pendidikan terakhir responden, domisili responden, frekuensi transportasi umum yang digunakan. Data-data tersebut dimuat pada tabel 2 sampai dengan tabel 7. Jenis responden yang dibedakan menjadi 2 tipe, yaitu non-disabilitas (ND) dan Kursi Roda (KR).

Tabel 2. Frekuensi jenis kelamin responden

\begin{tabular}{ccc}
\hline & Laki-laki & Perempuan \\
\hline Pengguna Kursi Roda & 9 & 3 \\
\hline Non-disabilitas & 13 & 5 \\
\hline
\end{tabular}

Tabel 3. Frekuensi usia responden

\begin{tabular}{ccccccccc}
\hline \multirow{2}{*}{ No } & \multirow{2}{*}{ Tipe } & Jumlah & \multicolumn{6}{c}{ Rentang Usia Responden } \\
\cline { 4 - 9 } & & & $15-20$ & $21-30$ & $31-40$ & $41-50$ & $51-60$ & $61-70$ \\
\hline 1 & KR & 12 & 0 & 4 & 3 & 3 & 1 & 1 \\
2 & ND & 18 & 2 & 8 & 1 & 2 & 5 & 0 \\
\hline
\end{tabular}

Tabel 4. Frekuensi pekerjaan responden

\begin{tabular}{ccccccc}
\hline \multirow{2}{*}{ No } & Tipe & Jumlah & \multicolumn{5}{c}{ Pekerjaan Responden } \\
\cline { 4 - 7 } & & & Pelajar/ Mahasiswa & Wirawasta & Karyawan & Lainnya \\
\hline 1 & KR & 12 & 1 & 2 & 2 & 7 \\
2 & ND & 18 & 7 & 3 & 1 & 7 \\
\hline
\end{tabular}


Tabel 5. Frekuensi pendidikan terakhir responen

\begin{tabular}{cccccccc}
\hline \multirow{2}{*}{ No } & \multirow{2}{*}{ Tipe } & \multirow{2}{*}{ Jumlah } & \multicolumn{5}{c}{ Pendidikan Terakhir Responden } \\
\cline { 4 - 8 } & & & SD/SMP & SMA/SMK & Diploma & S1 & S2/S3 \\
\hline 1 & KR & 12 & 2 & 3 & 0 & 7 & 0 \\
2 & ND & 18 & 0 & 6 & 0 & 7 & 5 \\
\hline
\end{tabular}

Tabel 6. Frekuensi domisi responden

\begin{tabular}{cccccccc}
\hline \multirow{2}{*}{ No } & \multirow{2}{*}{ Tipe } & Jumlah & \multicolumn{5}{c}{ Domisili Responden } \\
\cline { 4 - 8 } & & & Jakarta & Bogor & Depok & Tangerang & Bekasi \\
\hline 1 & KR & 12 & 5 & 2 & 0 & 3 & 2 \\
2 & ND & 18 & 11 & 2 & 1 & 3 & 1 \\
\hline
\end{tabular}

Tabel 7. Frekuensi transportasi umum yang digunakan

\begin{tabular}{ccc}
\hline & Kursi Roda & Non-disabilitas \\
\hline KRL & 5 & 5 \\
\hline MRT & 0 & 4 \\
\hline Transjakarta & 7 & 9 \\
\hline
\end{tabular}

Rangkuman hasil jawaban mengenai kondisi eksisting akan disajikan dalam tabel 8 sampai dengan tabel 14. Tabel tersebut terdiri atas variabel, tipe responden, jumlah responden, nilai minimum, nilai maksimum, dan mean.

Pada tabel 8, dapat dilihat bahwa tempat prioritas transportasi umum MRT, KRL, dan Transjakarta sudah cukup karena nilai mean yang berada diatas dari nilai tengah yaitu 2,5. Akan tetapi, perbedaan dari nilai tengah sangat kecil pada variabel tempat priortias di dalam transportasi umum, yang artinya bahwa tidak semua transportasi umum memiliki tempat prioritas untuk pengguna kursi roda.

Tabel 8. Area prioritas pengguna kursi roda di dalam transportasi umum

\begin{tabular}{ccccccc}
\hline No. & Variabel & Tipe & N & Min & Maks & Mean \\
\hline \multirow{2}{*}{1} & Tempat prioritas di dalam & KR & 12 & 1 & 4 & 2,58 \\
& transportasi umum & ND & 18 & 1 & 4 & 3,11 \\
\hline \multirow{2}{*}{2} & Penambat kursi roda di & KR & 12 & 1 & 4 & 2,75 \\
& dalam transportasi umum & ND & 18 & 1 & 4 & 2,95 \\
\hline \multirow{2}{*}{3} & Tempat prioritas yang & KR & 12 & 1 & 4 & 2,92 \\
& tersedia luas & ND & 18 & 2 & 4 & 2,79 \\
\hline
\end{tabular}

Pada tabel 9, dapat dilihat bahwa layanan yang diberikan oleh petugas transportasi umum sudah cukup baik. Hal ini dapat dilihat dari nilai mean yang berada diatas dari nilai tengah yaitu 2,5.

Tabel 9. Keberadaan petugas untuk pengguna kursi roda

\begin{tabular}{ccccccc}
\hline No. & Variabel & Tipe & N & Min & Maks & Mean \\
\hline \multirow{2}{*}{1} & Petugas menghimbau & KR & 12 & 1 & 4 & 2,83 \\
& $\begin{array}{c}\text { untuk mendahulukan } \\
\text { pengguna kursi roda }\end{array}$ & ND & 18 & 1 & 4 & 3,16 \\
\hline $\begin{array}{c}\text { Petugas membantu } \\
\text { pengguna kursi roda saat } \\
\text { hendak naik }\end{array}$ & KR & ND & 12 & 1 & 4 & 3,08 \\
\hline
\end{tabular}


Pada Tabel 10, dapat dilihat bahwa hasil dari responden pengguna kursi roda dan non-disabilitas kurang sependapat. Dapat dilihat bahwa, nilai mean dari variabel di atas mayoritas dibawah 2,5, yang menyatakan bahwa responden pengguna kursi roda kurang puas dengan fasilitas prasarana halte/stasiun. Tetapi beda halnya dengan responden pengguna non-kursi roda, nilai mean yang diperoleh dari semua variabel tersebut berada di atas 2,5, yang menunjukan mereka cukup puas dengan fasilitas prasarana halte/stasiun untuk pengguna kursi roda.

Tabel 10. Infrastruktur bagi pengguna kursi roda

\begin{tabular}{|c|c|c|c|c|c|c|}
\hline No. & Variabel & Tipe & $\mathrm{N}$ & Min & Maks & Mean \\
\hline \multirow{2}{*}{1} & \multirow{2}{*}{$\begin{array}{l}\text { Tinggi loket untuk } \\
\text { dicapai }\end{array}$} & $\mathrm{KR}$ & 12 & 1 & 4 & 2,50 \\
\hline & & ND & 18 & 1 & 3 & 2,95 \\
\hline \multirow{2}{*}{2} & \multirow{2}{*}{$\begin{array}{c}\text { Ruang berbelok leluasa } \\
\text { untuk dilewati }\end{array}$} & $\mathrm{KR}$ & 12 & 1 & 4 & 2,17 \\
\hline & & ND & 18 & 1 & 3 & 2,79 \\
\hline \multirow{2}{*}{3} & \multirow{2}{*}{$\begin{array}{l}\text { Pintu akses leluasa untuk } \\
\text { dilewati }\end{array}$} & $\mathrm{KR}$ & 12 & 1 & 4 & 2,42 \\
\hline & & ND & 18 & 1 & 4 & 2,79 \\
\hline \multirow{2}{*}{4} & \multirow{2}{*}{$\begin{array}{l}\text { Lebar koridor leluasa } \\
\text { untuk dilewati }\end{array}$} & $\mathrm{KR}$ & 12 & 1 & 4 & 2,58 \\
\hline & & ND & 18 & 1 & 3 & 3,00 \\
\hline \multirow[b]{2}{*}{5} & \multirow{2}{*}{$\begin{array}{l}\text { Tidak ada celah antara } \\
\text { prasarana dan sarana } \\
\text { transportasi }\end{array}$} & KR & 12 & 1 & 4 & 2,25 \\
\hline & & ND & 18 & 1 & 4 & 3,00 \\
\hline
\end{tabular}

Pada Tabel 11, dapat dilihat bahwa hasil dari variable-variabel tersebut berada diatas nilai tengah, yaitu 2,5. Pada variabel non-disabilitas tidak menggunakan tempat prioritas, memiliki nilai mean di bawah dengan nilai tengah, yang berarti bahwa non-disabilitas masih ada yang menggunakan tempat prioritas.

Tabel 11. Pengaruh pengguna non-disabilitas terhadap pengguna kursi roda

\begin{tabular}{ccccccc}
\hline No. & Variabel & Tipe & $\mathrm{N}$ & Min & Maks & Mean \\
\hline 1 & $\begin{array}{c}\text { Non-disabilitas tidak } \\
\text { menggunakan tempat } \\
\text { prioritas }\end{array}$ & KR & 12 & 1 & 4 & 2,50 \\
\hline & ND & 18 & 1 & 4 & 2,42 \\
\hline $\begin{array}{c}\text { Non-disabilitas } \\
\text { memberikan bantuan } \\
\text { terhadap pengguna kursi } \\
\text { roda }\end{array}$ & KR & 12 & 1 & 4 & 2,75 \\
\hline
\end{tabular}

Pada tabel 12, responden digabungkan, didapat bahwa untuk letak tombol bagi pengguna kursi roda, berada di bawah nilai tengah, yaitu 2,19, yang artinya bahwa tombol susah untuk dijangkau oleh pengguna kursi roda. Pendapat nondisabilitas pun juga sependapat.

Tabel 12. Lift yang terdapat pada stasiun MRT/KRL untuk pengguna kursi roda

\begin{tabular}{cccccc}
\hline No. & Variabel & N & Min & Maks & Mean \\
\hline 1 & Lift yang bisa diakses & 16 & 1 & 4 & 2,94 \\
2 & Tombol lift cukup untuk dijangkau & 16 & 1 & 3 & 2,19 \\
\hline
\end{tabular}

Pada tabel 13 dan 14, diperoleh bahwa nilai mean berada di atas nilai tengah, yaitu 2,5. Untuk fasilitas toilet sudah cukup tersedia, tetapi tidak memuaskan menurut kedua responden. Juga untuk pintu dorong dan kelandaian ramp, bahwa belum cukup memuaskan. 
Tabel 13. Toilet yang terdapat pada stasiun MRT/KRL untuk pengguna kursi roda

\begin{tabular}{cccccc}
\hline No. & Variabel & N & Min & Maks & Mean \\
\hline 1 & Toilet yang bisa digunakan & 16 & 1 & 4 & 2,69 \\
2 & Pegangan khusus untuk urinoir dan wc & 16 & 1 & 4 & 2,75 \\
3 & duduk & 16 & 1 & 4 & 2,50 \\
\hline
\end{tabular}

Tabel 14. Akses masuk/keluar trasnportasi Transjakarta untuk pengguna kursi roda

\begin{tabular}{cccccc}
\hline No. & Variabel & N & Min & Maks & Mean \\
\hline 1 & Ukuran pintu dorong masuk/keluar halte & 14 & 1 & 4 & 2,89 \\
2 & Kelandaian ramp untuk dilewati & 14 & 1 & 4 & 2,79 \\
3 & Pintu dorong ringan dilewati & 14 & 1 & 4 & 2,79 \\
\hline
\end{tabular}

Analisis yang dilakukan selanjutnya bertujuan untuk mengetahui kondisi eksisting yang dirasakan pengguna saat bertransportasi menggunakan KRL, MRT, dan Transjakarta di Jabodetabek. Analisis ini dilakukan dengan menggunakan metode One Sample T-Test dengan software SPSS. Responden berjumlah 30 orang, 12 orang diantaranya yaitu pengguna kursi roda, dan 18 orang pengguna transportasi umum sehari-hari yang memiliki kepedulian terhadap pengguna kursi roda. Variabel pertanyaan dibagi menjadi 4 kelompok besar, setiap kelompok memiliki beberapa pertanyaan untuk pengguna kursi roda dan non disabiltias. Kelompok ini memiliki kesamaan pertanyaan dari 3 transportasi umum. Untuk kelompok selanjutnya, yaitu pertanyaan yang belum ada pada semua transportasi umum. Pada kelompok ini dibagi untuk MRT/KRL dan Transjakarta. Setelah itu, dilakukan uji validitas dan reliabilitas dengan mengambil sampel acak sebanyak 5 responden. Hasil akan disajikan pada tabel 15 sampai dengan tabel 21.

Pada tabel 15 dan 16, dapat dilihat bahwa kelompok variabel area prioritas dan keberadaan petugas sudah valid semua. Maka dari itu akan diikutkan pada uji reliabilitas dan One Sample T-Test.

Tabel 15. Uji validitas area prioritas pengguna kursi roda di dalam transportasi umum

\begin{tabular}{ccccccc}
\hline No. & Variabel & Tipe & N & R & Sig. & Kriteria \\
\hline \multirow{2}{*}{1} & $\begin{array}{c}\text { Tempat prioritas di dalam } \\
\text { transportasi umum }\end{array}$ & KR & 5 & 0,949 & 0,007 & Valid \\
& ND & 5 & 0,921 & 0,013 & Valid \\
\hline \multirow{2}{*}{2} & $\begin{array}{c}\text { Penambat kursi roda di } \\
\text { dalam transportasi umum }\end{array}$ & KR & 5 & 0,894 & 0,020 & Valid \\
& Nempat prioritas yang & KR & 5 & 0,973 & 0,003 & Valid \\
\hline \multirow{2}{*}{$\begin{array}{c}\text { tersedia luas } \\
\end{array}$} & ND & 5 & 0,892 & 0,021 & Valid \\
\hline
\end{tabular}

Tabel 16. Uji validitas keberadaan petugas untuk pengguna kursi roda

\begin{tabular}{ccccccc}
\hline No. & Variabel & Tipe & N & R & Sig. & Kriteria \\
\hline 1 & $\begin{array}{c}\text { Petugas menghimbau } \\
\text { untuk mendahulukan } \\
\text { pengguna kursi roda }\end{array}$ & KR & 5 & 0,917 & 0,014 & Valid \\
\hline 2 & $\begin{array}{c}\text { Petugas membantu } \\
\text { pengguna kursi roda saat } \\
\text { hendak naik }\end{array}$ & KR & 5 & 0,917 & 0,014 & Valid \\
\hline
\end{tabular}

Pada tabel 17, dapat dilihat uji validitas kelompok variabel infrastruktur bagi pengguna kursi roda, ada 3 variabel pertanyaan yang tidak valid. Dari 3 pertanyaan yang tidak valid, ada satu pertanyaan yang tidak ada hasil angka, dikarenakan jawaban responden pengguna kursi roda yang seragam. Uji ini sudah diulangi beberapa kali dengan 
hasil yang sama, bahwa variabel pertanyaan tersebut tetap tidak valid. Pertanyaan yang tidak valid, tetap akan diikutkan pada uji reliabilitas dan One Sample T-Test dikarenakan jumlah responden yang terbatas.

Tabel 17. Uji validitas infrastruktur bagi pengguna kursi roda

\begin{tabular}{|c|c|c|c|c|c|c|}
\hline No. & Variabel & Tipe & $\mathrm{N}$ & $\mathrm{R}$ & Sig. & Kriteria \\
\hline \multirow[t]{4}{*}{1} & \multirow[t]{2}{*}{ Tinggi loket untuk dicapai } & $\mathrm{KR}$ & 5 & - & - & $\begin{array}{l}\text { Tidak } \\
\text { Valid }\end{array}$ \\
\hline & & ND & 5 & 0,918 & 0,014 & Valid \\
\hline & \multirow{2}{*}{$\begin{array}{l}\text { Ruang berbelok leluasa } \\
\text { untuk dilewati }\end{array}$} & $\mathrm{KR}$ & 5 & 0,725 & 0,083 & $\begin{array}{l}\text { Tidak } \\
\text { Valid }\end{array}$ \\
\hline & & ND & 5 & 1,000 & $>0,001$ & Valid \\
\hline \multirow[b]{2}{*}{-} & \multirow{2}{*}{$\begin{array}{l}\text { Pintu akses leluasa untuk } \\
\text { dilewati }\end{array}$} & $\mathrm{KR}$ & 5 & 0,296 & 0,314 & $\begin{array}{l}\text { Tidak } \\
\text { Valid }\end{array}$ \\
\hline & & ND & 5 & 1,000 & $>0,001$ & Valid \\
\hline \multirow[b]{2}{*}{4} & \multirow{2}{*}{$\begin{array}{c}\text { Lebar koridor leluasa } \\
\text { untuk dilewati }\end{array}$} & $\mathrm{KR}$ & 5 & 0,918 & 0,014 & Valid \\
\hline & & ND & 5 & 1,000 & $>0,001$ & Valid \\
\hline \multirow[b]{2}{*}{$د$} & \multirow{2}{*}{$\begin{array}{l}\text { Tidak ada celah antara } \\
\text { prasaranla uan saranla } \\
\text { transportasi }\end{array}$} & KR & 5 & 0,918 & 0,014 & Valid \\
\hline & & ND & 5 & 0,918 & 0,014 & Valid \\
\hline
\end{tabular}

Pada tabel 18, dapat dilihat bahwa uji validitas kelompok variabel pengaruh pengguna non-disabilitas terhadap pengguna kursi roda, mayoritas jawaban dari responden pengguna kursi roda maupun non-disabilitas tidak valid. Uji validitas pada kelompok variabel ini juga sudah dilakukan beberapa kali tes, dan juga mendapat hasil yang tidak valid.

Tabel 18. Uji validitas pengaruh pengguna non-disabilitas terhadap pengguna kursi roda

\begin{tabular}{|c|c|c|c|c|c|c|}
\hline No. & Variabel & Tipe & $\mathrm{N}$ & $\overline{\mathrm{R}}$ & Sig. & Kriteria \\
\hline \multirow[b]{2}{*}{1} & \multirow{2}{*}{$\begin{array}{l}\text { Non-disabilitas tidak } \\
\text { menggunakan tempat } \\
\text { prioritas }\end{array}$} & $\mathrm{KR}$ & 5 & 0,918 & 0,014 & Valid \\
\hline & & ND & 5 & 0,186 & 0,500 & $\begin{array}{l}\text { Tidak } \\
\text { Valid }\end{array}$ \\
\hline \multirow{2}{*}{2} & \multirow{2}{*}{$\begin{array}{l}\text { Non-disabilitas } \\
\text { memberikan bantuan } \\
\text { terhadap pengguna kursi }\end{array}$} & KR & 5 & 0,001 & 0,014 & $\begin{array}{l}\text { Tidak } \\
\text { Valid }\end{array}$ \\
\hline & & ND & 5 & 0,001 & 0,500 & $\begin{array}{l}\text { Tidak } \\
\text { Valid }\end{array}$ \\
\hline
\end{tabular}

Pada tabel 19 sampai dengan tabel 21, dapat dilihat bahwa fasilitas toilet, lift, dan akses masuk/keluar Transjakarta valid.

Tabel 19. Uji validitas fasilitas lift untuk pengguna kursi roda pada stasiun MRL/KRL

\begin{tabular}{cccccc}
\hline No. & Variabel & N & R & Sig. & Kriteria \\
\hline 1 & Lift yang bisa diakses & 5 & 0,973 & 0,003 & Valid \\
2 & Tombol lift cukup untuk dijangkau & 5 & 0,889 & 0,022 & Valid \\
\hline
\end{tabular}

Tabel 20. Uji validitas fasilitas toilet untuk pengguna kursi roda yang terdapat pada stasiun MRT/KRL

\begin{tabular}{cccccc}
\hline No. & Variabel & $\mathrm{N}$ & $\mathrm{R}$ & $\mathrm{Sig}$. & Kriteria \\
\hline 1 & Toilet yang bisa digunakan & 5 & 0,973 & 0,003 & Valid \\
2 & Pegangan khusus untuk urinoir dan wc & 5 & 0,973 & 0,003 & Valid \\
& duduk & 5 & 0,973 & 0,003 & Valid \\
\hline
\end{tabular}


Tabel 21. Uji validitas akses masuk/keluar trasnportasi Transjakarta untuk pengguna kursi roda

\begin{tabular}{ccccccc}
\hline No. & Variabel & $\mathrm{N}$ & $\mathrm{R}$ & \multirow{2}{*}{ Sig. } & Kriteria \\
1 & Ukuran pintu dorong masuk/keluar halte & 5 & 0,921 & & 0,013 & Valid \\
2 & Kelandaian ramp untuk dilewati & 5 & 0,918 & 0,014 & Valid \\
3 & Pintu dorong ringan dilewati & 5 & 0,947 & 0,007 & Valid \\
\hline
\end{tabular}

Pada uji reliabilitas, dilakukan dengan software yang sama, yaitu SPSS. Didapat hasil bahwa salah kelompok variabel tidak reliabel, yaitu pengaruh non-disabilitas terhadap pengguna kursi roda. Syarat apabila nilai Alpha Conbrach's lebih dari 0,6, dan dinyatakan sangat bagus apabila nilainya lebih besar dari 0,9.

Selanjutnya, hasil dari uji one sample t-test. Pada uji ini, sampel yang digunakan ada seluruh responden. Rangkuman data One Sample T-Test akan disajikan pada tabel 22. Pada tabel 22, bahwa dapat dilihat, bahwa sebagian besar hasilnya tidak signifikan. Variabel dikatakan tidak siknifikan jika nilai $\alpha$ nya dibawah 0,05 . Pada kelompok variabel area prioritas, menurut responden pengguna kursi roda kurang memuaskan dalam segi ketersediaan, penambat, dan luasannya. Tetapi menurut responden non-disabilitas, bahwa pada ketersediaan tempat prioritas, sudah cukup memuaskan. Pada keberadaan petugas, menurut responden pengguna kursi roda, bahwa petugas jarang menghimbau untuk untuk mendahulukan pengguna kursi roda, tetapi beda halnya dengan responden non-disabilitas, bahwa petugas jarang untuk membantu pengguna kursi roda naik. Pada infrastruktur untuk pengguna kursi roda, kedua responden setuju bahwa infrastruktur tersebut kurang memuaskan. Juga pada pengaruh non-disabilitas terhadap pengguna kursi roda, Menurut responden pengguna kursi roda bahwa kurangnya perhatian dari non-disabilitas itu sendiri, tetapi menurut non-disabilitas, bahwa seringkali non-disabilitas memberikan bantuan terhadap pengguna kursi roda. Dapat dilihat bahwa terkadang sudut pandang kedua responden berbanding terbalik.

Tabel 22. Rangkuman data AHP

\begin{tabular}{|c|c|c|c|}
\hline Kelompok & Pertanyaan & $\mathrm{KR}$ & ND \\
\hline \multirow{3}{*}{$\begin{array}{l}\text { Area prioritas untuk pengguna } \\
\text { kursi roda }\end{array}$} & Tempat prioritas di dalam transportasi umum & Tidak & Ya \\
\hline & Penambat untuk pengguna kursi roda di dalam & Tidak & Tidak \\
\hline & Tempat prioritas di dalam luas & Tidak & Tidak \\
\hline \multirow{2}{*}{ Keberadaan petugas } & $\begin{array}{c}\text { Petugas menghimbau untuk mendahulukan } \\
\text { pengguna kursi roda }\end{array}$ & Tidak & Ya \\
\hline & $\begin{array}{c}\text { Petugas membantu pengguna kursi roda saat } \\
\text { ingin naik }\end{array}$ & $\mathrm{Ya}$ & Tidak \\
\hline \multirow{5}{*}{$\begin{array}{l}\text { Infrastruktur untuk pengguna } \\
\text { kursi roda }\end{array}$} & Tinggi loket untuk dicapai & Tidak & Tidak \\
\hline & Ruang berbelok leluasa untuk dilewati & Tidak & Tidak \\
\hline & Pintu akses leluasa untuk dilewati & Tidak & Tidak \\
\hline & Lebar koridor leluasa untuk dilewati & Tidak & Tidak \\
\hline & Tidak ada celah antara sarana dan prasarana & Tidak & Tidak \\
\hline \multirow{2}{*}{$\begin{array}{l}\text { Pengaruh non-disabilitas untuk } \\
\text { pengguna kursi roda }\end{array}$} & $\begin{array}{l}\text { Non-disabilitas tidak menggunakan tempat } \\
\text { prioritas }\end{array}$ & Tidak & Tidak \\
\hline & $\begin{array}{l}\text { Non-disabilitas memberikan bantuan terhadap } \\
\text { pengguna kursi roda }\end{array}$ & Tidak & Ya \\
\hline \multirow{2}{*}{$\begin{array}{c}\text { Fasilitas lift pada stasiun } \\
\text { MRT/KRL }\end{array}$} & Lift yang bisa diakses & \multicolumn{2}{|c|}{ Tidak } \\
\hline & Tombol lift cukup untuk dijangkau & \multicolumn{2}{|c|}{ Tidak } \\
\hline \multirow{3}{*}{$\begin{array}{l}\text { Fasilitas toilet pada stasiun } \\
\text { MRT/KRL }\end{array}$} & Toilet yang bisa digunakan & \multicolumn{2}{|c|}{ Tidak } \\
\hline & Pegangan khusus dan wc duduk & \multicolumn{2}{|c|}{ Tidak } \\
\hline & Ruang untuk lutut di bawah wastafel & \multicolumn{2}{|c|}{ Tidak } \\
\hline \multirow{3}{*}{$\begin{array}{l}\text { Akses masuk/keluar } \\
\text { transjakarta }\end{array}$} & Ukuran pintu dorong & \multicolumn{2}{|c|}{ Tidak } \\
\hline & Kelandaian ramp & \multicolumn{2}{|c|}{ Tidak } \\
\hline & Pintu dorong ringan & \multicolumn{2}{|c|}{ Tidak } \\
\hline
\end{tabular}




\section{KESIMPULAN DAN SARAN}

\section{Kesimpulan}

Berdasarkan penelitian dan pengujian yang telah dilakukan, maka didapat kesimpulan bahwa kondisi eksisting layanan transportasi umum bagi pengguna kursi roda di MRT, KRL, dan Transjakarta, menganggap bahwa area prioritas di dalam transportasi umum untuk pengguna kursi roda belum terpenuhi. Menurut non-disabilitas bahwa tempat prioritas di dalam transportasi umum sudah tersedia dan memuaskan, tetapi tidak dengan penambat dan luasan area prioritas tersebut. Petugas yang membantu pengguna kursi roda saat ingin naik sudah memuaskan. Tetapi kurangnya himbauan dari petugas untuk mendahulukan. Menurut responden non-disabilitas, berbanding terbalik. Infrastruktur untuk pengguna kursi roda tidak cukup memuaskan. Hal ini sependapat dengan responden nondisabilitas. Pengaruh pengguna non-disabilitas terhadap pengguna kursi roda tidak cukup memuaskan. Tetapi, responden non-disabilitas berpendapat bahwa non-disabilitas sudah memberikan bantuan kepada pengguna kursi roda. fasilitas lift, toilet, dan akses masuk/keluar tersedia, tetapi tidak cukup memuaskan untuk digunakan oleh pengguna kursi roda.

\section{Saran pemanfaatan penelitian}

Penelitian ini dapat dimanfaatkan sebagai pertimbangan dan perencanaan fasilitas kebutuhan transportasi umum untuk pengguna kursi roda di Jabodetabek dan perbaikan fasilitas yang sudah tersedia. Terutama untuk bagian infrastruktur, jawaban responden pengguna kursi roda untuk loket, koridor, akses masuk/keluar, tombol lift, dan ruang berbelok perlu diperluas, agar meningkatkan kemudahan dan kenyamanan untuk pengguna kursi roda. Juga diperlukan perluasan akses pintu masuk/keluar sarana dan prasarana.

\section{Saran terhadap penelitian selanjutnya}

Jumlah responden pengguna kursi roda yang menggunakan transportasi umum lebih diperbanyak, agar hasil penelitian lebih akurat. Juga dapat ditambahkan responden non-disabilitas agar memiliki jawaban dengan sudut pandang berbeda. Bahasa pertanyaan kuesioner lebih dipermudah, karena tidak semua responden memiliki pendidikan yang setara. Pertanyaan dibuat dengan kata sehari-hari yang biasa digunakan untuk berkomunikasi. Pembagian kuesioner lebih baik dilakukan secara langsung, tanpa google form. Kuesioner ditanyakan langsung kepada responden agar lebih jelas, responden dapat langsung bertanya kepada pembuat kuesioner maksud dari pertanyaan yang kurang dimengerti. Dalam penelitian ini, melibatkan responden pengguna kursi roda. Pengguna kursi roda juga memiliki komunitas yang cukup besar. Jika ingin memperluas jangkauan penyebaran kuesioner, dapat dilakukan dengan meminta kontak narasumber kepada dosen pembimbing, dan membagikannya secara online.

\section{DAFTAR PUSTAKA}

Douglas, R., et al. "The LSU reciprocating gait orthosis" 6 (1983)

Kobetic and E.B. Marsolais. "Muscle selection and walking performance of multichannel FES systems for ambulation in paraplegia" 5 (1997): 23-29.

Kobetic, R., et al. "Development of hybrid orthosis for standing, walking, and stair climbing after spinal cord injury" 3 (2009): 46.

Louie, D.R., J.J. Eng and T. Lam. "Gait speed using powered robotic exoskeletons after spinal cord injury: a systematic review and correlational study" 12 (2015): 82.

Munce, S.E., et al. "Impact of quality improvement strategies on the quality of life and well-being of individuals with spinal cord injury" 2 (2013): 14.

Tarsidi, Didi. "Kendala Umum yang dihadapi Penyandang Disabilitas” 10 (2011).

Undang-Undang No. 25 Tahun 2009 tentang Pelayanan Publik 
Kebutuhan Layanan Transportasi Umum bagi Pengguna

Raymond Teng, et al. Kursi Roda di Jabodetabek 